\title{
Laparoscopic anterior resection
}

\section{R. J. Heald}

Published online: 13 February 2010

(C) Springer-Verlag 2010

This truly is twenty-first century "state of the art" teaching technology! The only slight drawback is that it may give the young surgeon the idea that anyone can do it! Michael $\mathrm{Li}$ is one of the world's most accomplished laparoscopic surgeons, operating in his own superb multi-endoscopic operating room in Hong Kong, with a well-drilled team to back him up. The young aspiring laparoscopic operator must break himself in on benign disease and recognise that the low pelvic dissection poses special challenges especially in cancer cases. In most parts of the world, any cancer larger than $6 \mathrm{~cm}$ would be regarded as a contraindication to the laparoscopic method and the lowest anastomoses are also problematic if done via the peritoneal cavity with staplers. Cancers nearer than $6 \mathrm{~cm}$ to the anal verge require an expert laparoscopic rectal surgeon, so 6 is a number to remember!

With those provisos in mind, this is a delightful exposition of the laparoscopic surgeon's craft. It parades the viewer through an eclectic mix of electro-surgical instruments. Early on the harmonic scalpel shows the pros and cons of ultrasonic dissection with its tell tale vapour cloud, while both the atlas and the advance utilise the bipolar electric energy of ligasure.

Both a hook and the tip of the advance are used for monopolar diathermy where the essence is to put structures on stretch so as to display the areolar tissue that characterises the "holy plane" around the embryologically midline visceral mesentery of the gut-mesocolon or mesorectum. The oncological quality of the specimen and the reduction of involved margins to a minimum depend on the care taken to avoid tearing and to follow precisely the correct plane without burrowing into the mesenteric fatty tissue.

The choice of scissors, monopolar diathermy or one of the bipolar or ultrasonic devices is a critical matter of personal choice for each surgeon.

We live in a world of rapidly developing technological alternatives for the achievement of surgical objectivesopen surgery, laparoscopy, and now robotics. In cancer surgery, it is crucial that each of these can be assessed in terms of measurable auditable outcomes-the naked eye quality of the specimen, the confirmation of tumour free margins by microscopic evaluation, the recognition and preservation of surrounding structures such as nerve plexuses, and ultimately the survival and quality of life of the patient. The fact that the most modern technologies can be offered to the widest audiences is one of the greatest guarantees of safety in the choices which so many surgeons have to make over the next few years.

This comment refers to the article doi: 10.1007/s10151-009-0557-4.

R. J. Heald ( $\square)$

Pelican Cancer Foundation, The Ark, Dinwoodie Drive,

Basingstoke, Hampshire RG24 9NN, UK

e-mail: E.Hayward@pelicancancer.org

URL: www.pelicancancer.org 